28 Colin-Jones DG. Management of dyspepsia: report of a working party. Lancet 1988;i:576-9.

29 Johnsen R, Bernersen B, Straume B, Førde OH, Bostad L, Burhol PG. Prevalences of endoscopic and histological findings in subjects with and without dyspepsia. BMF 1991;302:749-52.

30 Coghlan JG, Gilligan D, Humphries H, McKenna D, Dooley C, Sweeney E, et al. Campylobacter pylori and recurrence of duodenal ulcers - a 12 month follow-up study. Lancet 1987;ii:1109-11.

31 Loffeld RJLF, Potters HVJP, Stobbenringh E, Flendrig JA, Van Spreeuwel JP, Arends JW. Campylobacter associated gastritis in patients with nonulcer dyspepsia: a double blind placebo controlled trial with colloidal bismuth subcitrate. Gut 1989;30:1206-12.

32 Al-Moagel MA, Evans DH, Abdulghani ME, Adam E, Evans DJ, Malaty $\mathrm{HM}$, et al. Prevalence of Helicobacter pylori infection in Saudi Arabia, and com ex Am f Gastroenterol 1990;85:944-7.
33 Jones DM, Lessels AM, Eldridge J. Campylobacter-like organisms on the gastric mucosa: culture, histological, and serological studies. $f$ Clin Pathol 984;37:1002-6.

34 Marshall BJ, McGechie DB, Rogers PA, Glancy RJ. Pyloric campylobacter infection and gastroduodenal disease. Med f Aust 1985;142:439-44.

35 Villako K, Maards H, Tammur R, Keevallik R, Peetsalu M, Sipponen P, et al. Helicobacter pylori infestation and the development and progression of chronic gastritis: results of long-term follow-up examinations of a random sample. Endoscopy 1990;22:114-7.

36 Tatsuta $M$, Iishi $\mathrm{H}$, Okuda $\mathrm{S}$. Location of peptic ulcers in relation to antral and fundal gastritis by chromoendoscopic follow up examinations. Dig Dis $S$ ci 1986;31:7-11.

37 Lawson HH. Effect of duodenal contents on the gastric mucosa under experimental conditions. Lancet 1964;i:469-72.

(Accepted 24 February 1992)

\title{
Investigation of long term problems after obstetric epidural anaesthesia
}

\author{
C MacArthur, M Lewis, E G Knox
}

\section{Abstract \\ Objective-To examine the association between obstetric epidural anaesthesia and subsequent long term problems. \\ Design-Postal questionnaire on health problems after childbirth linked to maternity case note data. \\ Setting-Maternity hospital in Birmingham. \\ Subjects-11 701 women who delivered their most recent child during $1978-85$ and who returned completed questionnaires. \\ Main outcome measures-Frequencies of long} term symptoms after childbirth.

Results -Compared with the 6935 women who did not have epidural anaesthesia the $\mathbf{4 7 6 6}$ women who did more commonly experienced backache (903 $(18.9 \%)$ with epidural $v 731(10.5 \%)$ without epidural), frequent headaches $220(4.6 \%) v 199(2.9 \%)$ ), migraine $(92(1.9 \%)$ v $73(1 \cdot 1 \%))$, neckache (116 $(2.4 \%) v 112(1.6 \%))$, and tingling in hands or fingers $(143(3.0 \%) v 150(2 \cdot 2 \%))$. The results could not be explained by correlated social or obstetric factors. The associations with head, neck, and hand symptoms were found only in women who reported backache. An excess of visual disturbances among women who had epidural anaesthesia $(83(1.7 \%) v$ $91(1 \cdot 3 \%)$ ) was present only in association with migraine, but excess of dizziness or fainting (102 $(2 \cdot 1 \%) v 109(1 \cdot 6 \%)$ ) was independent of other symptoms. 26 women had numbness or tingling in the lower back, buttocks, and leg, of whom 23 had had epidural anaesthesia. Of 34 women with spinal headache, nine (five after accidental dural puncture; four after spinal block) reported long term headaches.

Conclusions-These associations may indicate a causal sequence, although this cannot be proved from this type of study. Randomised trials of epidural anaesthesia are required to determine whether causal relations exist.

\section{Introduction}

Various investigators have reported short term sequelae of epidural anaesthesia, ${ }^{1-5}$ but these studies have generally not examined symptoms after hospital discharge. We previously reported a relation between epidurals and subsequent backache. ${ }^{6}$ We report here an investigation of other long term symptoms after obstetric epidural anaesthesia.

\section{Subjects and methods}

The details of the methods and background to this investigation have been described. ${ }^{67}$ Briefly, the study population consisted of 11701 women who had delivered their most recent child at Birmingham Maternity Hospital between 1978 and 1985. The inquiry was undertaken in January 1987, so the deliveries had occurred at least 13 months previously; the longest follow up period was nine years.

Data were assembled from two sources. The first was the computerised file of maternity case notes, which provided social, obstetric, and anaesthetic data, and the second was postal questionnaires sent to the addresses in the case notes to obtain information on subsequent long term health problems. Twenty five symptoms were specified, and the women were asked whether they had experienced each problem since delivering the index child; if so, they were asked how soon after the birth it had occurred, when it had stopped, whether they had had it before, and whether they had sought medical advice. An open question was also included for reporting any other symptoms.

From this information we defined relevant long term symptoms as those that had started within three months after delivery, had lasted more than six weeks, and had never been experienced before. Recurring symptoms and those inadequately dated were excluded from the main analyses. Unfortunately, we obtained no information on symptom severity and this will be the subject of further investigation.

During the study period 30096 women had delivered at the hospital, but many women had moved from their case note addresses. Using electoral register and Pos Office sources, we were able to estimate that the 11701 who returned completed questionnaires represented a response rate of at least $78 \%$ of those who had received a questionnaire. An examination of the case notes of the non-returners showed that their obstetric and anaesthetic characteristics were similar to those of the respondents.

We used discriminant analysis to establish differences in early events and discriminating circumstances between women who did and did not have symptoms. This procedure takes simultaneous account of a large number of variables and calculates which of them are independent and significant predictors of a particular symptom. It eliminates spurious associations between epidural anaesthesia and subsequent symptoms, which might arise from the fact that this form of anaesthesia is generally associated with less straightforward deliveries (table I) that could also produce subsequent effects. Variables were examined and selected in a stepwise manner, the most significant association being selected first, then the next most significant, and so on. All the associations with epidural anaesthesia reported here were significant after this form of 
statistical standardisation. The analyses were repeated for each type of delivery. We divided vaginal deliveries into normal and abnormal. Normal was defined as singleton, occipitoanterior presentation, spontaneous onset of labour, first stage $<12$ hours, second stage $<2$ hours, and no forceps. Abnormal deliveries were characterised by one or more of twins, atypical presentation, induced labour, first stage $\geqslant 12$ hours, second stage $\geqslant 2$ hours, and forceps. Detailed methods are available from us on request.

\section{Results}

Of the 11701 responders, 4766 had had epidural anaesthesia for pain relief in labour or for caesarean section and 6935 had not.

\section{BACKACHE}

We have already reported an association between epidural anaesthesia and subsequent long term backache, after normal and abnormal vaginal deliveries and emergency caesarean sections (table II). ${ }^{6}$ We have further analysed the results for three times of onset after delivery (table III). Backaches in all three groups were associated with epidural anaesthesia, including those starting one to three months after delivery. This suggests the presence of a latent injury for which additional postpartum events such as lifting or bending are sometimes necessary to trigger the symptom. However, long term backaches starting 3-12 months after delivery were not more common in the epidural

TABLE I-Associations between epidural anaesthesia and delivery characteristics

\begin{tabular}{|c|c|c|}
\hline Factors & $\begin{array}{c}\text { No }(\%) \text { of women } \\
\text { who had an } \\
\text { epidural } \\
(\mathrm{n}=4766)\end{array}$ & $\begin{array}{c}\text { No }(\%) \text { of women } \\
\text { who had no } \\
\text { epidural } \\
(\mathrm{n}=6935)\end{array}$ \\
\hline Primiparous & $2326(48 \cdot 8)$ & $1859(26 \cdot 8)^{\star \star \star}$ \\
\hline Under 25 years & $1106(23 \cdot 2)$ & $1519(21.9)$ \\
\hline Married & $4287(89 \cdot 9)$ & $6238(89.9)$ \\
\hline Social class I or II & $1263(26 \cdot 5)$ & $1699(24 \cdot 5)^{\star \star}$ \\
\hline White origin & $4170(87 \cdot 5)$ & $5965(86 \cdot 0)^{\star}$ \\
\hline Asian origin & $202(4 \cdot 2)$ & $328(4 \cdot 7)$ \\
\hline Afro-Caribbean origin & $103(2 \cdot 2)$ & $285(4 \cdot 1)^{\star \star \star}$ \\
\hline Hypertension & $615(12 \cdot 9)$ & $444(6 \cdot 4)^{\star \star \star}$ \\
\hline Antepartum haemorrhage & $129(2 \cdot 7)$ & $201(2 \cdot 9)$ \\
\hline Induced labour & $942(19 \cdot 8)$ & $494(7 \cdot 1)^{\star \star \star}$ \\
\hline Occipitoanterior presentation & $3922(82 \cdot 3)$ & $6343(91 \cdot 5)^{\star \star \star}$ \\
\hline Multiple pregnancy & $111(2 \cdot 3)$ & $58(0 \cdot 8)^{\star \star \star}$ \\
\hline lst stage $\geqslant 6 \mathrm{~h}$ & $1331(27 \cdot 9)$ & $864(12 \cdot 5)^{\star \star \star}$ \\
\hline 2 nd stage $\geqslant 1 \mathrm{~h}$ & $2035(42 \cdot 7)$ & $762(11 \cdot 0)^{\star \star \star}$ \\
\hline Straight forceps delivery & $1436(30 \cdot 1)$ & $422(6 \cdot 1)^{\star \star \star}$ \\
\hline Keilland's forceps delivery & $378(7 \cdot 9)$ & $65(0 \cdot 9)^{\star \star \star}$ \\
\hline Elective caesarean section & $426(8.9)$ & $344(5 \cdot 0)^{\star \star \star \star}$ \\
\hline Emergency caesarean section & $652(13 \cdot 7)$ & $493(7 \cdot 1)^{\star \star \star}$ \\
\hline Episiotomy & $2702(56 \cdot 7)$ & $2410(34 \cdot 8)^{\star \star \star}$ \\
\hline Laceration & $633(13 \cdot 4)$ & $2255(32 \cdot 5)^{\star \star \star}$ \\
\hline Postpartum haemorrhage & $882(18 \cdot 5)$ & $610(8 \cdot 8)^{\star \star \star}$ \\
\hline Preterm birth & $310(6 \cdot 5)$ & $492(7 \cdot 1)$ \\
\hline Birth weight $>3700 \mathrm{~g}$ & $1197(25 \cdot 1)$ & $1567(22 \cdot 6)^{\star \star \star}$ \\
\hline Head circumference $>35$ & $1178(24 \cdot 7)$ & $1281(18 \cdot 5)^{\star \star \star}$ \\
\hline Length $>54 \mathrm{~cm}$ & $791(16 \cdot 6)$ & $893(12.9)^{\star \star \star}$ \\
\hline $\begin{array}{l}\text { Admitted to special care baby } \\
\text { unit }\end{array}$ & $510(10 \cdot 7)$ & $645(9.3)^{\star}$ \\
\hline Breast feeding at discharge & $3184(66 \cdot 8)$ & $4750(68 \cdot 5)$ \\
\hline
\end{tabular}

group $(151,3 \cdot 2 \%)$ than in the non-epidural group (206, $3 \cdot 0 \%)$.

\section{FREQUENT HEADACHES AND MIGRAINE}

First experience of frequent headaches was reported by $220(4 \cdot 6 \%)$ women who had epidural anaesthesia compared with $199(2.9 \%)$ who had no epidural $(\mathrm{p}<0.001) ; 92(1.9 \%)$ reported first ever migraine compared with $73(1 \cdot 1 \%)(\mathrm{p}<0 \cdot 001)$. The same pattern was observed in women who reported both symptoms - often a double reporting of the same symptom - and in those who reported one without the other. Discriminant analyses confirmed epidural anaesthesia as a significant and independent predictor of both symptoms.

Table II compares the occurrence of headaches in women who had normal and abnormal vaginal deliveries and caesarean sections. The excesses of frequent headaches and migraine after epidural anaesthesia were found in women who had had both normal and abnormal vaginal deliveries; the abnormal features did not account for these excess symptoms. After caesarean sections, however, the headache rates were relatively high in women who did and did not have epidural anaesthesia. Unlike the association with backache, the association with headache was limited to symptoms starting in the first week (table III).

\section{BACKACHE AND HEADACHE IN ASIAN WOMEN}

There were 530 women of Asian origin in the sample and these women reported substantially more backache and headache than did white women (table IV). The association with epidural anaesthesia was still present so that Asian women who had epidural anaesthesia reported extremely high rates for both symptoms. Limb symptoms were also more common in Asian women.

\section{SPINAL HEADACHE}

A spinal headache was recorded in the maternity case notes of 34 women as a complication of the puerperium. This record referred to the characteristic postural headache after spinal anaesthesia (13 women) or after an accidental dural puncture during epidural anaesthesia (21 women). This type of headache is generally believed to subside, even if untreated, within about a week. ${ }^{8}$ However, nine of the 34 women reported that the headache lasted more than six weeks, and of these, five had had headaches for more than a year. Five of these longer term headaches occurred after a known accidental dural puncture $(0 \cdot 1 \%$ of all epidural anaesthetisations) and four after a spinal block ( $2 \cdot 5 \%$ of all spinal blocks administered).

\section{NECKACHE AND TINGLING IN THE HANDS OR FINGERS}

Neckache was reported by $116(2 \cdot 4 \%)$ women after epidural anaesthesia compared with $112(1.6 \%)$ after deliveries without epidural anaesthesia $(p<0.01)$; tingling in the hands was reported by $143(3.0 \%)$ compared with $150(2 \cdot 2 \%)(\mathrm{p}<0 \cdot 01)$. Both differences

TABLE II -Number (percentage) of women with symptoms associated with epidural anaesthesia, according to type of delivery

\begin{tabular}{|c|c|c|c|c|c|c|c|c|}
\hline Delivery & Backache & $\begin{array}{l}\text { Frequent } \\
\text { headaches }\end{array}$ & Migraine & Neckache & $\begin{array}{l}\text { Tingling } \\
\text { hands }\end{array}$ & $\begin{array}{c}\text { Visual } \\
\text { disturbance }\end{array}$ & Dizzy or faint & $\begin{array}{c}\text { Total No of } \\
\text { women }\end{array}$ \\
\hline \multicolumn{9}{|l|}{ Normal vaginalt: } \\
\hline With epidural & $200(181 \cdot 2)^{\star \star \star}$ & $56(5 \cdot 1)^{\star \star \star}$ & $20(1 \cdot 8)^{\star}$ & $27(2.5)^{\star}$ & $35(3 \cdot 2)^{\star}$ & $19(1 \cdot 7)$ & $20(1 \cdot 8)$ & 1098 \\
\hline No epidural & $474(10 \cdot 2)$ & $114(2 \cdot 5)$ & $45(1 \cdot 0)$ & $65(1.4)$ & $90(1.9)$ & $53(1 \cdot 1)$ & $64(1 \cdot 4)$ & 4646 \\
\hline \multicolumn{9}{|l|}{ Abnormal vaginalł: } \\
\hline With epidural & $513(19 \cdot 7)^{\star \star \star}$ & $121(4 \cdot 6)^{\star}$ & $56(2 \cdot 1)^{\star}$ & $59(2 \cdot 3)$ & $75(2 \cdot 9)$ & $42(1 \cdot 6)$ & $62(2 \cdot 4)$ & 2610 \\
\hline No epidural & $163(11 \cdot 2)$ & $47(3 \cdot 2)$ & $16(1 \cdot 1)$ & $27(1.9)$ & $40(2 \cdot 8)$ & $19(1 \cdot 3)$ & $21(1 \cdot 4)$ & 1452 \\
\hline \multicolumn{9}{|l|}{ Caesarean section: } \\
\hline With epidural & $190(17 \cdot 6)^{\star \star \star}$ & $43(4 \cdot 0)$ & $16(1 \cdot 5)$ & $30(2 \cdot 8)$ & $33(3 \cdot 0)$ & $22(2 \cdot 0)$ & $20(1.9)$ & 1078 \\
\hline No epidural & $94(11 \cdot 2)$ & $38(4 \cdot 5)$ & $12(1.4)$ & $20(2 \cdot 4)$ & $20(2 \cdot 4)$ & $19(2 \cdot 3)$ & $24(2 \cdot 9)$ & 837 \\
\hline
\end{tabular}

${ }^{\star} \mathrm{p}<0.05,{ }^{\star \star \star} \mathrm{p}<0.001$.

tNormal vaginal delivery defined as singleton, occipitoanterior presentation, spontaneous onset of labour, lst stage $<12$ hours, 2nd stage $<2$ hours, no forceps.

$\ddagger$ Abnormal vaginal deliveries delivered as one or more of twins, atypical presentation, non-spontaneous onset of labour, 1 st stage $\geqslant 12$ hours, 2 nd stage $\geqslant 2$ hours, forceps. 
TABLE III - Time of onset of backache and frequent headaches or migraine after childbirth in women who did and did not have epidural anaesthesia

\begin{tabular}{|c|c|c|c|c|}
\hline & 1st Week & 2-4 Weeks & 1-3 Months & $\begin{array}{l}\text { Total No of } \\
\text { women }\end{array}$ \\
\hline \multicolumn{5}{|l|}{ Backache: } \\
\hline Epidural & $573(12 \cdot 0)^{\star \star \star}$ & $172(3 \cdot 6)^{\star \star \star}$ & $158(3 \cdot 3)^{\star \star \star}$ & 4766 \\
\hline No epidural & $455(6 \cdot 6)$ & $141(2 \cdot 0)$ & $135(1.9)$ & 6935 \\
\hline \multicolumn{5}{|c|}{ Headache or migraine: } \\
\hline Epidural & $157(3 \cdot 3)^{\star \star \star}$ & $54(1 \cdot 1)$ & $56(1 \cdot 2)$ & 4766 \\
\hline No epidural & $95(1 \cdot 4)$ & $58(0 \cdot 8)$ & $92(1 \cdot 3)$ & 6935 \\
\hline
\end{tabular}

TABLE IV-Numbers (percentages) of Asian and white women with backache and headaches according to whether they received epidural anaesthesia for childbirth

\begin{tabular}{lccc}
\hline & Backache & Headache & $\begin{array}{c}\text { Total No of } \\
\text { women }\end{array}$ \\
\hline Epidural: & $61(30 \cdot 2)^{\star \star \star}$ & $19(9 \cdot 4)^{\star \star}$ & 202 \\
Asian & $780(18 \cdot 7)$ & $201(4 \cdot 8)$ & 4170 \\
White & $52(15 \cdot 9)^{\star \star}$ & $20(6 \cdot 1)^{\star \star}$ & 328 \\
No epidural: & $614(10 \cdot 3)$ & $179(3 \cdot 0)$ & 5965 \\
Asian & & \\
White & &
\end{tabular}

were independently significant after discriminant analysis. The difference remained for normal vaginal deliveries alone (table II), but after abnormal vaginal deliveries and caesarean sections the incidence was similar for women who did and did not have epidural anaesthesia. Caesarean sections were associated with higher rates of symptoms regardless of the type of anaesthesia used. For neckache, only onset in the first week was associated with epidural anaesthesia, whereas for tingling in the hands only onset at 2-13 weeks was associated.

\section{SPINAL AXIS COMBINATIONS}

Backache, headache, neckache, and tingling in the hands and fingers were closely interrelated. Many women with backache reported one or more of the other symptoms. To determine whether the relation between epidural anaesthesia and backache could explain the other associations, we conducted discriminant analyses of each of the individual symptoms including backache as an independent (controlling) variable. In no case did epidural anaesthesia remain a significant predictor of spinal axis symptoms other than backache. Complex multiway tabulations confirmed this finding. The relation between epidural anaesthesia and these symptoms was present only in women who had backache. They can probably be regarded as extensions of an epidural associated symptom complex, of which backache is the main component.

\section{VISUAL DISTURBANCES AND DIZZINESS OR FAINTING}

Dizziness or fainting episodes were reported by 102 $(2 \cdot 1 \%)$ of the women who had epidural anaesthesia compared with $109(1.6 \%)$ who did not $(\mathrm{p}<0.05)$. Visual disturbances were reported by $83(1 \cdot 7 \%)$ women after epidural anaesthesia and 91 (1.3\%) after deliveries without epidural anaesthesia. Both differences were significant after discriminant analyses, although the crude difference for visual disturbances was not significant. For normal and abnormal vaginal deliveries the crude differences were not significant for either symptom. And for caesarean sections relatively high rates occurred both with and without epidural anaesthesia (table II).

Visual disturbances were often reported with migraine (odds ratio $20 \cdot 2$ ), so we examined this symptom separately in women with and without migraine. The association between epidural anaesthesia and visual disturbances was present only when disturbances occurred jointly with migraine. This was confirmed by discriminant analysis. The association between epidural anaesthesia and visual disturbances was therefore deemed to be secondary.

Dizziness or fainting was also reported more often with migraine (odds ratio $12 \cdot 1$ ). However discriminant analysis including migraine as a confounding variable showed that epidural anaesthesia remained an independent predictor. Only dizziness or fainting starting within a week of delivery was associated with epidural anaesthesia.

\section{PARAESTHESIAS}

In response to an open ended question about unlisted symptoms 22 women reported numbness or tingling in the lower back, buttocks, or upper leg and a further four reported the same symptom in the lower leg. Of these 26 women, 23 had had epidural anaesthesia. This difference was highly significant and was independent of backache.

\section{DURATION OF SYMPTOMS}

Although we defined long term symptoms as those lasting longer than six weeks, most had in fact lasted much longer. About two thirds were still present at the time of our inquiry. It was clear that many problems had become chronic. Discriminant analyses of symptoms associated with epidural anaesthesia for different durations were consistent with each other and did not alter any of the findings described above.

\section{Discussion}

We have found several long term symptoms associated with epidural anaesthesia in addition to backache, which we had already reported. ${ }^{6}$ These other symptoms were all less common than backache, several were related anatomically to the spinal axis and were related statistically to backache. Among the spinal axis symptoms backache was dominant; headache (including migraine), neckache, and tingling in the hands were related to epidural anaesthesia only when reported jointly with backache.

We previously postulated that backache after obstetric epidural anaesthesia could result from postural problems during labour and that the effect is exacerbated when both mobility and discomfort feedback are inhibited by epidural block. ${ }^{6}$ Many symptoms began in the first week after delivery but in some women backache and tingling in the hands did not appear until several weeks after the birth, although they were still associated with epidural anaesthesia. This suggests initial stresses which in some cases required additional postpartum triggers to precipitate symptoms. For headache and neckache, however, only symptoms of immediate onset were clearly associated with epidural anaesthesia and for tingling in the hands, only later onset. The sequence of symptom generation is probably complex.

Asian women showed the same relative excess of backache and headache after epidural anaesthesia as white women, but they also had several other symptoms not related to epidural anaesthesia. These symptoms probably arise from osteomalacia, and this suggests an additional dimension to the generation of spinal axis symptoms. The postpartum symptoms of Asian women are the subject of another paper.

Long term spinal headaches were reported after four $(2 \cdot 5 \%)$ spinal blocks and five $(0 \cdot 1 \%)$ epidural anaesthetisations. These headaches are generally believed to resolve quickly even if untreated, ${ }^{8}$ and this belief is therefore called into question. Kitzinger also noted that headache after dural tap sometimes persisted for many weeks, although the number of women affected was not given.' This report was based on a non-random sample of 453 women readers of 
an Australian parent's magazine and of 455 attending National Childbirth Trust meetings who had responded to a query about their experience of epidural anaesthesia and subsequent effects. Improvements in anaesthetic technique, especially the use of different needles, may alter the risk of spinal headache. Nevertheless, in view of the recent increase in use of subarachnoid anaesthesia for caesarean section, further examination of the association with spinal headaches, even though based on small numbers, is urgently required.

Paraesthesias in the legs and lower back were also mentioned by Kitzinger. ${ }^{9}$ Our data on numbness or tingling in the legs or lower back were elicited only in response to an open question so may have underestimated the incidence. Such data, for the same reason, are also more susceptible to reporting bias among women who had an epidural anaesthesia. Nevertheless, the difference was highly significant and unexplained by backache and deserves further consideration.

Visual disturbances and dizziness or fainting were not specifically mentioned by Kitzinger, although some women described a kind of sensory confusion. ${ }^{9}$ We found that both of these symptoms were associated with migraine, and the association between epidural anaesthesia and visual disturbances seemed to be secondary to the association with migraine. For dizziness or fainting, however, it was less clear whether the same applied. Further research is needed to elucidate this point.

We have identified independent associations between several long term symptoms after childbirth and epidural anaesthesia. Care was taken to avoid reporting bias and there was no evidence of enhanced reporting of other symptoms by women who had epidural anaesthesia ${ }^{67}$ Nevertheless, a hidden factor

might account for these associations. Further examination with different investigational methods including randomised trials, is needed. The impact of the symptoms on the women's lives also needs to be assessed. Epidural analgesia is unquestionably the most effective form of pain relief available for labour ${ }^{10-12}$ and as such is used by large numbers of women. ${ }^{13}$ These next stages of inquiry are therefore urgent.

Dr J Selwyn Crawford participated in the original design of the study until his death in August 1988. We thank the women who took part in the study. The work was funded by a grant from the Department of Health.

1 Crawford JS. Lumbar epidural block in labour: a clinical analysis. Br $\mathcal{F}$ Anaest 1972; 44:66-70

2 Crawford JS. Principles and practice of obstetric anaesthesia. 5th ed. Oxford: Blackwell Scientific, 1985

3 Crawford JS. Some maternal complications of epidural analgesia for labour Analgesia 1985;40:1219-25.

4 Moore J, Murraghan GA, Lewis MA. A clinical evaluation of the materna effects of extradural analgesia for labour. Anaesthesia 1974;29:537-40.

5 Ramanathan S. Obstetric anaesthesia. Philadelphia: Lea and Febiger, 1988.

6 MacArthur C, Lewis M, Knox EG, Crawford JS. Epidural anaesthesia and long term backache after childbirth. BMF 1990:301:9-12.

7 MacArthur C, Lewis M, Knox EG. Health after childbirth. London: HMSO, 1991.

8 Brownridge $P$. The management of headache following accidental dural puncture in obstetric patients. Anaesth Intensive Care 1983;11:4-15.

9 Kitzinger S. Some women's experiences of epidurals: a descriptive study. London National Childirinh Trust, 1987.

10 Morgan BM, Bulpitt CJ, Clifton P, Lewis PJ. Analgesia and satisfaction in childbirth. Lancet 1982;ii:808-10.

11 Robinson JO, Rosen M, Evans JM, Revill S, David H, Rees GAD. Materna opinion about analgesia for labour. A controlled trial between epidural block and intra-muscular pethidine combined with inhalation. Anaesthesia 1980 35:1173-81

12 Philipsen T, Jensen NH. Maternal opinion about analgesia in labour and delivery. A comparison of epidural blockade and intra-muscular pethidine. Eur J Obstet Gynecol Reprod Biol 1990;34:205-10.

13 Hibbard BM, Scott DB. The availability of epidural anaesthesia and analgesia in obstetrics. Br $\mathcal{F}$ Obstet Gynaecol 1990;97:402-5.

(Accepted 10 March 1992)

\section{Treatment of natal cleft sinus: a prospective clinical and economic evaluation}

\section{H T Khawaja, S Bryan, P C Weaver}

Department of Surgery, St Mary's Hospital,

Portsmouth

H T Khawaja, FRCS, senior registrar

PC Weaver, FRCS,

consultant

Health Economics Research Group, Brunel

University, Uxbridge, Middlesex

S Bryan, MSC, research fellow

Correspondence to:

Mr H T Khawaja,

Department of Surgery

(Firm III Office), King's

College Hospital, London

SE5 9RS.

BMF 1992;304:1282-3
Many surgical techniques are used for treating natal cleft sinus, yet recurrence rates are high. ${ }^{1}$ This study evaluated two commonly used treatments: excision and primary closure, and excision and healing by secondary intention.

\section{Patients, methods, and results}

Among adult patients with symptomatic natal cleft sinus, those with abscess formation or diabetes mellitus, those on steroids, and those judged unsuitable for day case surgery were excluded from the trial. Over 49 months, 46 consecutive patients entered the trial and were randomly allocated to a treatment group by a system of sequentially numbered opaque sealed envelopes.

Surgery was undertaken under general anaesthetic. Following excision, primary closure was achieved with deep mattress prolene sutures and the patients discharged home on the same day (group 1), or the cavity was packed with gauze soaked with aqueous proflavine; the pack was changed daily and the patient allowed home when packing was tolerable without parenteral analgesia (group 2).

All patients were reviewed weekly until healing occurred and also six and 12 months later. Healing was defined as complete epithelialisation of the operative site. In group 2 the proflavine pack was changed daily for the first week and replaced by a silicone foam, which was renewed weekly until healing occurred. In group 1 the sutures were removed on the 14th postoperative day. If primary closure failed the wound was allowed to heal by granulation.

Length of admission, outpatient visits, district nurse visits, days off work, days to complete healing, and recurrence at six and 12 months were measured. An "intention to treat" analysis ${ }^{2}$ was used for between group comparisons. Confidence intervals for population differences between medians were calculated based on the median differences between the unpaired samples of observations.

The table compares the groups and describes the outcome variables. In group 2 all patients had complete healing of the wound with no recorded complications.

Outcome of treatment of natal cleft sinus by excision and primary closure or excision and secondary healing. Values are medians unless otherwise stated

\begin{tabular}{lccc}
\hline & $\begin{array}{c}\text { Group 1- } \\
\text { primary } \\
\text { closure } \\
(\mathrm{n}=23)\end{array}$ & $\begin{array}{c}\text { Group 2- } \\
\text { secondary } \\
\text { healing } \\
(\mathrm{n}=23)\end{array}$ & $\begin{array}{c}\text { Median difference } \\
\text { between groups } \\
(95 \% \text { confidence } \\
\text { intervals })\end{array}$ \\
\hline Age (years) & 25 & 23 & NA \\
Sex (male:female ratio) & $19: 4$ & $17: 6$ & NA \\
$\begin{array}{l}\text { No of pits } \\
\text { No of days in hospital }\end{array}$ & 2 & 2 & NA \\
$\begin{array}{l}\text { No of days to healing } \\
\text { No of days off work }\end{array}$ & $14 \dagger$ & 3 & NA \\
$\begin{array}{l}\text { No of outpatient visits } \\
\text { No of visits by district } \\
\text { nurse }\end{array}$ & 2 & 41 & $-23(-28$ to -20$)$ \\
\hline
\end{tabular}

NA $=$ not applicable

Day case surgery.

† Sutures removed on the 14th postoperative day. 